\title{
Maternal and environmental factors affecting the nutritional status of children in an urban slum of Ludhiana
}

\author{
Ragini $^{1}$, Shikha $^{2 *}$ \\ 1,2Tutor, Community Medicine Department, PMCH, Patna INDIA. \\ Email: dr.shikha2000@gmail.com
}

Abstract Background: Child malnutrition occurs as a result of both economic conditions and poor nutritional awareness. The education of women has been found to play a pivotal role in improving the health of children. Aim: To assess maternal and environmental factors affecting the nutritional status of children in an urban slum of Ludhiana. Material and Methods: The malnourished children aged 2-5 years in the study population, were listed, from the available data-base of the Department. This slum, named Premnagar, has a population of 10,206. A total of 100 malnourished 2-5 years old children were studied for environmental and maternal factors such as socioeconomic status and education level. Results: Upper lower class family children were more malnourished followed by lower middle class children. Children who lived in pukka house were more malnourished. Literate mothers had more malnourished child in compared to illiterate mothers. Mothers who were not working had more malnourished child in compared to working mothers. Conclusion: Mother should be properly educated regarding the nutritional needs of the growing children and importance of complete immunization. Appropriate dietary modifications should be done to ensure the increased calorie and protein intake as per the recommendations.

Keywords: Children, malnutrition, slum area, environmental factors, maternal factors

*Address for Correspondence:

Dr. Shikha, Tutor, Community Medicine, PMCH, Patna, INDIA.

Email: dr.shikha2000@gmail.com

Received Date: 20/11/2019 Revised Date: 12/12/2019 Accepted Date: 11/01/2020

DOI: https://doi.org/10.26611/10111321

\begin{tabular}{|l|l|}
\hline \multicolumn{2}{|c|}{ Access this article online } \\
\hline Quick Response Code: & Website: \\
\hline & www.medpulse.in \\
& \\
\hline
\end{tabular}

\section{INTRODUCTION}

Nutrition is a significant part of health and development. Better nutrition leads to improved infant, child and maternal health, stronger immune systems, safer pregnancy and childbirth, lower risk of non-communicable diseases and longevity. Malnutrition results from imbalanced diet which can occur from scarcity of suitable foods, lack of purchasing ability of the family, traditional beliefs and taboos about feeding the baby. ${ }^{1}$ Punjab, the breadbasket of India, also called "the granary of India", has very poor statistics on the health of women and children. The National Family Health Survey (NFHS-3) 2005-2006 conducted under the supervision of the Ministry of Health and Family Welfare, Government of India, showed that $37 \%$ of the under-five children in Punjab are stunted, one in ten is wasted and almost one fourth are underweight. ${ }^{2}$ In Ludhiana, the picture is grim in the slums. Panda et al (1993) found $87.3 \%$ of under-five years old children in an urban slum in Ludhiana to be malnourished. ${ }^{3}$ In another slum of Ludhiana et al (2010) reported $74 \%$ of the underfive children to be stunted, $42 \%$ wasted and $29.5 \%$ underweight. ${ }^{4}$ Child malnutrition occurs as a result of both economic conditions and poor nutritional awareness. The education of women has been found to play a pivotal role in improving the health of children. Mother's nutritionrelated knowledge, attitudes and practices appears to be strongly associated with children's nutritional status. ${ }^{5-7} \mathrm{The}$ purpose of this study was to assess maternal and environmental factors affecting the nutritional status of children in an urban slum of Ludhiana. 


\section{MATERIAL AND METHODS}

Study settings

The urban slum of Field Ganj is a field practice area of the Department of Community Medicine, Christian Medical College, Ludhiana, Punjab. The Department provides primary health care services to approximately 20,000 population in this area through its Urban Training Centre. It has a well-established system of constant community monitoring by the use of the Family Folder methodology, a health information system developed and maintained by the Department, wherein each family in the population served has a Family Folder containing the demographic and health profile of the members of the family. The homes are visited regularly in a beat visit fashion by a health team consisting of a female Multi-purpose Health Worker (MPHW) and a medical intern to provide targeted, home-based primary health care and advice, and to update the demographic and health information. Information regarding the current nutritional status of the under-5 children was, therefore, available from the data-base of the area under study.

Study design

\section{Study population}

A community-based Observational study.

Hundred malnourished children between the age group 2-5 years who reside in the study population area. Study tools and data collection

The malnourished children aged 2-5 years in the study population, were listed, from the available data-base of the Department. This slum, named Premnagar, has a population of 10,206 . In this population there were 112 malnourished 2-5 years old children. Allowing for $10 \%$ loss to follow-up or non-response, a minimum of 100 eligible children were proposed to be studied. A pre-tested questionnaire was used to collect data after explaining the nature and purpose of the study to the respondents and obtaining signed informed consent from them. The respondents were the mothers of the children. All children included in the study had a complete history and physical examination. The immunization card of the children was also consulted to confirm vaccination status. At the baseline level, all the children who were found eligible for the study had their anthropometric indices measured and entered in a mother-retained growth chart. The height/length was measured to the nearest $0.5 \mathrm{~cm}$ using a stadiometer, and the weight was measured with light clothing using electronic scales.

The median weight-for-age, height-for-age and weightfor-height of the NCHS standard were used as the reference anthropometric indices for this study (WHO 2006).

- Underweight used here to indicate children whose weight was $<75$ per cent of the median weight-for- age value which is equivalent to $2^{\text {nd }}$ and $3^{\text {rd }}$ degrees of malnutrition according to Gomez classification.

- $\quad$ Stunted refers to children whose height was $<2 \mathrm{SD}$ below the mean height-for-age value. This is an index of shortness and has been proposed as an indicator of chronic malnutrition.

- Wasted refers to children whose weight was $<2$ $\mathrm{SD}$ below the mean weight-for-height value. This is an index of thinness and is claimed to be an indicator of acute malnutrition.

All the children were de-wormed to remove the confounding effect of worm infestation on weight gain and nutritional status. There was no intervention at this stage.

Malnutrition was graded according to Gomez Classification.

- 1 st degree (mild) malnutrition: Between 75-89\% of the expected weight-for-age

- 2nd degree (moderate) malnutrition: Between 60$74 \%$ of the expected weight-for-age

- 3rd degree (severe) malnutrition: Under $60 \%$ of the expected weight-for-age

The socio-economic status was measured by using Modified Prasad's Classification.

Statistical analysis

The data were analyzed using EpiInfo version-6 software and SPSS version 16. The mean and standard deviation (SD) of the weight gain, the increase in height and the increase in MUAC were calculated and compared before and after the trial. Repeated measures ANOVA were calculated for comparison of the four means. Paired t-test and Chi-square test were applied, as appropriate, to assess statistical significance.

\section{RESULTS}

In the 101 children studied, 57(56.4\%) were in first degree, $42(41.6 \%)$ in second degree and $2(2 \%)$ in third degree malnutrition. Because of very small numbers, for subsequent statistical analysis those in third degree malnutrition have been combined with second degree malnutrition. Female children were more malnourished. In second degree, female children were more in number. There was equal number one in each male and female in third degree. Most affected age groups of the children were 24-35 months and least affected age groups were 48-59 months. In both the age groups, there was one in each third degree malnourished child. This was also statistically significant. Children with low birth weight were more malnourished but both third degree malnourished children were more than 2500 grams birth weight.First born children were more malnourished. Children with birth order $>=3$ were less malnourished. There were more second degree malnourished children in second birth order. 
Table 1: Nutritional status of the children according to age and sex

\begin{tabular}{|c|c|c|c|c|c|}
\hline \multirow{2}{*}{ Variables } & \multicolumn{3}{|c|}{ Malnutrition Grade } & \multirow{2}{*}{$\begin{array}{c}\text { Chi-square } \\
\text { value }\end{array}$} & \multirow{2}{*}{ P value } \\
\hline & Istdegree & IInd/IIIrddegree & Total & & \\
\hline \multicolumn{6}{|l|}{ Sex } \\
\hline Male & $29(60.4 \%)$ & $19(39.6 \%)$ & $48(47.5 \%)$ & \multirow{2}{*}{0.59} & \multirow{2}{*}{0.44} \\
\hline Female & $28(52.8 \%)$ & $25(47.2 \%)$ & $53(52.4 \%)$ & & \\
\hline \multicolumn{6}{|l|}{ Age of the child } \\
\hline $12-23 \mathrm{~m}$ & $8(32.0 \%)$ & 17 (68.0\%) & $25(24.7 \%)$ & & \\
\hline $24-35 \mathrm{~m}$ & $21(58.3 \%)$ & 15 (41.7\%) & $36(35.6 \%)$ & \multirow{3}{*}{9.23} & \multirow{3}{*}{0.02} \\
\hline $36-47 m$ & $18(72.0 \%)$ & 7 (28.0\%) & $25(24.7 \%)$ & & \\
\hline $48-59 \mathrm{~m}$ & $10(66.7 \%)$ & $5(33.3 \%)$ & $15(14.8 \%)$ & & \\
\hline \multicolumn{6}{|l|}{ Birth weight } \\
\hline$<2500$ gms & 33 (57.9\%) & $24(42.1 \%)$ & $57(56.4 \%)$ & \multirow[t]{2}{*}{0.11} & \multirow[t]{2}{*}{0.73} \\
\hline$>2500$ gms & $24(54.5 \%)$ & $20(45.4 \%)$ & 44 (43.5\%) & & \\
\hline \multicolumn{6}{|l|}{ Birth order } \\
\hline 1 & $28(68.3 \%)$ & $13(31.7 \%)$ & $41(40.6 \%)$ & \multirow{3}{*}{4.49} & \multirow{3}{*}{0.10} \\
\hline 2 & 17 (44.7\%) & $21(55.3 \%)$ & $38(37.6 \%)$ & & \\
\hline$\geq 3$ & $12(54.5 \%)$ & $10(45.4 \%)$ & $22(21.7 \%)$ & & \\
\hline
\end{tabular}

Children who lived in joint family were more malnourished in compared to nuclear family child which was also statistically significant.Upper lower class family children were more malnourished followed by lower middle class children. Children who lived in pukka house were more malnourished.

Table 2: Sociodemographic characteristics of study population

\begin{tabular}{|c|c|c|c|c|c|}
\hline \multirow[b]{2}{*}{ Variables } & \multirow[b]{2}{*}{ Ist degree } & \multicolumn{2}{|c|}{ Malnutrition grade } & \multirow[b]{2}{*}{$\begin{array}{l}\text { Chi square } \\
\text { value }\end{array}$} & \multirow[b]{2}{*}{$P$ value } \\
\hline & & $\begin{array}{l}\text { IInd/IIIrd } \\
\text { degree }\end{array}$ & Total & & \\
\hline \multicolumn{6}{|l|}{ Type of family } \\
\hline Nuclear & $19(44.2 \%)$ & $24(55.8 \%)$ & $43(42.6 \%)$ & \multirow[t]{2}{*}{4.57} & \multirow[t]{3}{*}{0.03} \\
\hline Joint & $38(65.5 \%)$ & $20(34.5 \%)$ & $58(57.4 \%)$ & & \\
\hline \multicolumn{5}{|l|}{ Socioeconomic status } & \\
\hline Class I & $1(100.0 \%)$ & 0 & $1(0.9 \%)$ & \multirow{5}{*}{3.37} & \multirow{5}{*}{0.33} \\
\hline Class II & $2(50.0 \%)$ & $2(50.0 \%)$ & $4(3.9 \%)$ & & \\
\hline Class III & $16(51.6 \%)$ & $15(48.3 \%)$ & $31(30.7 \%)$ & & \\
\hline Class IV & $29(53.7 \%)$ & $25(46.3 \%)$ & $54(53.5 \%)$ & & \\
\hline Class V & $9(81.8 \%)$ & $2(18.1 \%)$ & $11(10.9 \%)$ & & \\
\hline \multicolumn{6}{|l|}{ Type of house } \\
\hline Kuccha & $8(42.1 \%)$ & $11(57.9 \%)$ & $19(18.8 \%)$ & \multirow{3}{*}{2.06} & \multirow{3}{*}{0.35} \\
\hline Pukka & $34(58.6 \%)$ & $24(41.4 \%)$ & $58(57.4 \%)$ & & \\
\hline Semipukka & $15(62.5 \%)$ & $9(37.5 \%)$ & $24(23.7 \%)$ & & \\
\hline & \multicolumn{3}{|c|}{ Malnutrition grade } & \multirow{3}{*}{$\begin{array}{c}\text { Chi-square } \\
\text { value }\end{array}$} & \multirow[b]{2}{*}{$P$ value } \\
\hline Variables & First degree & $\begin{array}{c}\text { Second/Third } \\
\text { degree }\end{array}$ & Total & & \\
\hline \multicolumn{5}{|l|}{ Mother's age at childbirth } & \\
\hline$<21$ years & $1(100.0 \%)$ & 0 & $1(0.9 \%)$ & \multirow{3}{*}{0.37} & \multirow{3}{*}{0.54} \\
\hline $21-30$ years & $40(54.0 \%)$ & $34(46.0 \%)$ & $74(73.3 \%)$ & & \\
\hline$>30$ years & $16(61.5 \%)$ & $10(38.4 \%)$ & $26(25.7 \%)$ & & \\
\hline \multicolumn{6}{|l|}{ Mother's education } \\
\hline Illiterate & $13(48.1 \%)$ & $14(51.8 \%)$ & $27(26.7 \%)$ & \multirow{3}{*}{1.04} & \multirow{3}{*}{0.59} \\
\hline Middle school & $18(60.0 \%)$ & $12(40 \%)$ & $30(29.7 \%)$ & & \\
\hline High school and above & $26(59.0 \%)$ & $18(40.9 \%)$ & $44(43.5 \%)$ & & \\
\hline \multicolumn{6}{|l|}{ Mother's occupation } \\
\hline Not working & $45(57.6 \%)$ & $31(39.7 \%)$ & $78(78.8 \%)$ & \multirow{3}{*}{0.00} & \multirow{3}{*}{0.96} \\
\hline Working at home & $11(57.8 \%)$ & $8(42.1 \%)$ & $19(19.2 \%)$ & & \\
\hline Working outside & $1(50.0 \%)$ & $1(50.0 \%)$ & $2(2.0 \%)$ & & \\
\hline
\end{tabular}


Children whose mothers were in age group of 21-30 years at their birth were more malnourished but first degree was more in percentage whose mothers were $>30$ years. Literate mothers had more malnourished child in compared to illiterate mothers. Mothers who were not working had more malnourished child in compared to working mothers.

\section{DISCUSSION}

General under-nutrition, characterized by under-weight among children is more prevalent amongst rural children, scheduled castes and tribes, and amongst children with illiterate mothers. The contributing factors for undernutrition according to World Bank Report 2009 are Imbalanced diet, household food insecurity and intrahousehold food distribution, gender inequality, inadequate preventative and curative health services and insufficient knowledge of proper care and infant feeding practices. Due to the low social status of Indian women, their diet often lacks in both quality and quantity. So, women suffer from malnutrition and less likely to have healthy babies. Also in India, mothers generally lack proper knowledge in feeding children. Consequently, new born infants are unable to get adequate amount of nutrition from their mothers. Poverty, high food prices, bad dietary practices and agricultural productivity. Diarrhoea and other infections can also lead to malnutrition through decreased nutrient absorption, decreased intake of food, increased metabolic requirements, and direct nutrient loss. Parasite infections can also lead to malnutrition. ${ }^{8}$ In present study, out of 101 children studied, 57(56.4\%) were in first degree, 42 $(41.6 \%)$ in second degree and $2(2 \%)$ in third degree malnutrition. Goel et al conducted a study in Rohtak, a city in Haryana on 540 children aged 1-6 years. The study found that $57.4 \%$ children were malnourished. Out of which Grade I 107(19.8\%), Grade II 137(25.4\%), Grade III $45(8.3 \%)$ and Grade IV 21 (3.9\%). ${ }^{9}$ Steinohff MC et al conducted a cross sectional survey of the nutritional status of 1223 preschool age children in a development area in the southern Indian state of Tamil Nadu. They found that $45 \%$ of the children were underweight (low weight for age), $51 \%$ were stunted (low height for age) and $21 \%$ were wasted (low weight for height). ${ }^{10}$ In our study, most affected age groups of the children were 24-35 months and least affected age groups were 48-59 months. In both the age groups, there was one in each third degree malnourished child. Avachat $e t$ al conducted a study in six villages of rural Maharashtra. They found that malnutrition is a problem that affects $56.93 \%$ children in the age group $1-2$ years and $52.8 \%$ children in the age group $2-3$ yrs. The prevalence of malnutrition was significantly more in 1-3 years age group. ${ }^{11}$ Rao $\mathrm{S}$ et al studied 845 children in the age group of $0-5$ years from three slums in Pune, Maharashtra for a period of 2 years. Peak prevalence of malnutrition was observed around 18 months and shorter period (3.5 months) of exclusive breastfeeding was probably responsible. ${ }^{12}$ It was observed that female children were more malnourished. In second degree, female children were more in number. There was equal number one in each male and female in third degree. In present cultural practices, males are always favored. A Mittal et al had done study in 1-5-year-old children living in urban slum population Tripuri Town, Patiala. Lower grades (I and II) were more common among males than females $(35.29 \%$ vs $32.85 \%)$, whereas severe grades (III and IV) were common in females $(5.71 \%$ vs $2.94 \%)$. However, the results were statistically insignificant. ${ }^{13}$ However, Goel et al found no significant association between nutritional status and sex of the child $(\mathrm{p}=0.928) .{ }^{9}$ In our study, upper lower class family children were more malnourished followed by lower middle class children. Children who lived in pukka house were more malnourished.A number of nutrition and diet surveys carried out among the child population groups in various parts of the country have confirmed the existence of widespread malnutrition among the poorer section of population. Approximately, one out of every three children under five in developing countries is malnourished. ${ }^{14}$ The major cause of under-nutrition has always been reported to be poverty along with ignorance. Poverty has a vicious cycle. Poverty leads to inadequate food intake and undernutrition, further leading to impaired physical growth and development of children, impaired functioning, low productivity again leading to poverty. However, in our study, literate mothers had more malnourished child in compared to illiterate mothers. Mothers who were not working had more malnourished child in compared to working mothers. Mittal et al conducted a study to determine the effect of various maternal factors on the prevalence of underweight and stunting among 1-5-yearold children in urban slum population Tripuri Town, Patiala. Mother's education seemed to play a protective role against child's malnutrition. Overall $70.75 \%$ of the mothers were literate though up to different levels. Prevalence was the highest where mothers were illiterate $(60.9 \%)$ vs. value of $21.2 \%$ where mother had education more than high school. ${ }^{13}$

\section{CONCLUSION}

Literate but non-working mothers had more malnourished child in our study. Therefore, Mother should be properly educated regarding the nutritional needs of the growing children and importance of complete immunization. Appropriate dietary modifications should be done to ensure the increased calorie and protein intake as per the recommendations. Mother should be taught to monitor the 
growth of their children by regular weighting their children and noting on the WHO growth charts.

\section{REFERENCES}

1. Park K. Park's Textbook of Preventive and social Medicine,BanarsidasBhanot, Jabalpur, 2011;pp.506.

2. National Family Health Survey (NFHS-3), 2005-2006, Government of India, Ministry of

Health and Family Welfare, Madhya Pradesh.

3. Panda P, Benjamin AI, Zachariah P. Health Status of Underfives in a LudhianaSlum, Health and Population - Perspectives and Issues 1993;16:133-141.

4. Sengupta P, Philip N, Benjamin AI. Epidemiological Correlates of Undernutrition inUnder-5 years old Children in an Urban Slum of Ludhiana, Health and Population-Perspectives and Issues 2010;33:1-9.

5. Abbi R, Christian P, Gujaral S, Gopaldas T. Mothers nutrition knowledgeand child nutritional status in India.Food Nutr Bull1988;10:51-54.

6. Gupta MC, Mehrotra M, Arora S, Saran M. Relation of childhood malnutrition to parental education and mothers nutrition-related KAP.Ind J Ped1991;58:269-274.
7. Bhat IA, Shah GN, Dhar GM, Mehnaz S. A study of the impact ofMaternal knowledge and practice on the nutritional status of infants. Ind J Mat Child Health1992;3:12-15.

8. Musaiger, Abdulrahman O, Hassan, Abdelmonem S, Obeid, Omar. The Paradox of Nutrition-Related Diseases in the Arab Countries: The Need for Action. Int J Environ Res Pub Health $2011 ; 8: 3637-3671$.

9. Goel MK, Mishra R, Gaur D, Das A. Nutrition surveillance in 1-6 years old children in urban slum of a city in Northern India. The Int J Epidem 2007;5(1).

10. Steinhoff MC, Hilder AS, Srilatha VL, Mukarji D. Prevalence of malnutrition in Indian preschool children: a survey of wasting and stunting in rural Tamil Nadu, 1983. Bulletin of World Health Organization 1986; 64(3):457-63.

11. Avachat S, Phalke V, Phalke D. Epidemiological study of malnutrition (under nutrition) among under five children in a section of rural area. Pravara Med Rev 2009; 4(2):20-22.

12. Rao S, Joshi SB, Kelkar RS. Changes in nutritional status and morbidity over time among pre-school children from slums in Pune, India. Indian Pediatrics 2000;37:1060-71.

13. Mittal A, Singh J, Ahluwalia SK. Effect of Maternal Factors on Nutritional Status of 1-5-Year-Old Children in Urban Slum Population. Ind J Comm Med 2007;32(4):264-267.

14. Gulati JK. Child malnutrition: Trends and Issues. Anthropologist 2010;12:131-140.

Source of Support: None Declared Conflict of Interest: None Declared 